NAVAS, Iván; JAAR, Antonia. "La responsabilidad penal de las personas jurídicas en la jurisprudencia chilena".

Polít. crim. Vol. 13, No 26 (Diciembre 2018) Art. 10, pp. 1027-1054.

[http://www.politicacriminal.cl/Vol_13/n_26/Vol13N26A10.pdf]

\title{
La responsabilidad penal de las personas jurídicas en la jurisprudencia chilena
}

\section{Corporate Criminal liability in Chilean case law}

\author{
Iván Navas Mondaca \\ Doctor en Derecho Penal Universidad Pompeu Fabra. \\ Profesor Asistente de Derecho Penal \\ Universidad San Sebastián \\ ivan.navas@uss.cl \\ Antonia Jaar Labarca \\ Licenciada en Ciencias Jurídicas \\ Pontificia Universidad Católica de Chile \\ ajaar@uc.cl
}

\section{Resumen}

El presente trabajo presenta un estudio crítico de la jurisprudencia chilena que se ha pronunciado sobre la responsabilidad penal de las personas jurídicas. El objetivo es analizar cómo los tribunales están comprendiendo y aplicando la teoría del delito a los casos en que se atribuye responsabilidad penal a un ente colectivo. Se pone especial atención tanto en la aplicación de los requisitos legales para hacer responsable a la persona jurídica como en el deber de motivación de las sentencias penales. El trabajo pone de manifiesto la posible vulneración de un derecho fundamental al debido proceso con base en la falta de motivación por parte de los tribunales al momento de fundamentar la responsabilidad penal de las personas jurídicas.

Palabras clave: Personas jurídicas, responsabilidad penal, jurisprudencia.

\begin{abstract}
This paper presents a critical study of the Chilean case law pronounced on the Corporate Criminal Liability. The objective is to critically analyse how the Courts are understanding and applying the theory of crime in cases where criminal responsibility is attributed to a collective entity. Special attention is given to the application of legal requirements to consider liable the legal person and the duty of motivating criminal sentences. The paper highlights the possible violation of a fundamental right to due process based on the lack of motivation of the courts when it comes to substantiating the Corporate Criminal Liability.
\end{abstract}

Key words: Corporate Criminal Liability, case law

\section{Zusammenfassung}

Der Beitrag stellt eine kritische Studie der chilenischen Rechtsprechung dar, die sich zur 
Polit. crim. Vol. 13, № 26 (Diciembre 2018) Art. 10, pp. 1027-1054.

[http://www.politicacriminal.cl/Vol_13/n_26/Vol13N26A10.pdf]

strafrechtlichen Verantwortung juristischer Personen ausspricht. Das Ziel besteht darin, kritisch zu analysieren, wie das Gerichte die Verbrechenslehre verstehen und anwenden, und zwar in Fällen, in denen strafrechtliche Verantwortung einer kollektiven Einheit zugeschrieben wird. Besonderes Augenmerk wird auf die Anwendung der gesetzlichen Bestimmungen gelegt, um die juristische Person haftbar $\mathrm{zu}$ machen, wie in der Pflicht, Strafurteile zu motivieren. Das Artikel legt die mögliche Verletzung eines Grundrechts auf einen ordnungsgemäßen Prozess dar, das auf der mangelnden Begründung der Gerichte beruht, wenn es darum geht, die strafrechtliche Verantwortung juristischer Personen zu begründen.

Stichworter: strafrechtliche juristischer Personen, Rechtsprechungs.

\section{Introducción}

En noviembre del año 2009 se promulgó la Ley Nº 20.393 que establece la responsabilidad penal de las personas jurídicas por delitos de lavado de activos, financiamiento del terrorismo, cohecho y receptación ${ }^{1}$. Con la aparición de la responsabilidad penal de las personas jurídicas se deja atrás el principio societas delinquere non potest que imperaba en el ordenamiento jurídico chileno y que parecía dominar la tradición europea continental hasta hace poco $^{2}$.

La finalidad del establecimiento de una responsabilidad penal a personas jurídicas pasa por dos grandes argumentos. Uno político criminal cuyos componentes principales son la insuficiencia preventiva de la responsabilidad penal individual; a la existencia de una irresponsabilidad organizada de sujetos individuales que actuaban bajo el paraguas jurídico de la persona jurídica y por último la falta de eficacia preventiva de formas de responsabilidad colectiva no penales como el derecho administrativo sancionador ${ }^{3}$. En el caso de Chile también se debe sumar los compromisos internacionales como las recomendaciones de la OCDE para que Chile pudiese entrar como miembro pleno. El otro argumento que debería estar más o menos claro es el fin de la pena para las personas jurídicas. Sin embargo, en la Ley 20.393 que establece la responsabilidad penal de la persona jurídica no resulta fácil identificar. Al respecto se puede señalar que tiene un fin preventivo general y que se desprende por las medidas preventivas de autorregulación que se exigen a la persona jurídica que eviten o prevengan el delito cometido por las personas físicas que integran la persona jurídica ${ }^{4}$.

\footnotetext{
${ }^{1}$ El delito de receptación se incorporó al catálogo en virtud de la Ley 20.931 conocida como “Agenda Corta Anti-delincuencia" publicada el 5 de julio de 2016.

${ }^{2}$ Entre los países que se enmarcan en la tradición del derecho europeo continental que han expandido la responsabilidad penal a las personas jurídicas se encuentran España, Italia, Austria, Suiza. En el caso de Alemania no existe responsabilidad penal de las personas, sino que las sanciones a las empresas concurre por vía administrativa mediante la aplicación de multas en virtud de una Ley de Contravenciones administrativas.

${ }^{3}$ Véase SILVA SÁNCHEZ, Jesús, "La responsabilidad penal de las personas jurídicas en derecho español”, Comunicaciones en Propiedad Industrial y Derecho de la Competencia, $\mathrm{n}^{\circ} 65$ (2012), pp. p.11.

${ }^{4}$ NIETO MARTIN, Adán, La responsabilidad penal de las personas jurídicas: Un modelo legislativo, Madrid: Iustel, 2008, pp. 266 y ss.
} 
NAVAS, Iván; JAAR, Antonia. "La responsabilidad penal de las personas jurídicas en la jurisprudencia chilena".

Ahora bien, a pesar de la existencia de opiniones críticas sobre una auténtica responsabilidad penal de las personas jurídicas ${ }^{5}$, la Ley establece expresamente que ellas son penalmente responsables. Una comprensión del derecho penal en términos rígidos y absolutos sería un obstáculo que nos impida avanzar en la solución de los desafíos que impone la sociedad moderna del riesgo. Es cierto que la teoría del delito tal cual se formuló dificulta la aplicación en un ente colectivo. Sin embargo, el derecho penal y la teoría del delito es un medio para la solución de los problemas que se presentan. Si ese problema no tiene solución con la configuración actual, el camino es avanzar en el desarrollo de un sistema lógico y racional de aplicación de las normas jurídicas a sistemas de injusto distintos de los que tradicionalmente se conocen ${ }^{6}$.

El rechazo a priori de la posibilidad de sancionar penalmente a las personas jurídicas y de otros fenómenos complejos harían del derecho penal un conjunto de normas petrificadas que no tienen en consideración su objeto final: la realidad a la cual deben dar respuesta. En este sentido, no se comparten las críticas de Gracia Martín cuando señala que las tesis favorables a la responsabilidad penal de las personas jurídicas son "opiniones y afirmaciones apenas argumentadas y hechas de un vacío de teoría jurídica que no se sustenta en absoluto en el mínimum minimorum del saber jurídico permanente válido y, por esto, de obligada observancia y respeto"7. En nuestra opinión, ese saber jurídico permanente válido tiene que ser aquel que surge de la permanente revisión de sí mismo y, como señalaba Schmitt, «de las modificaciones impuestas por la irrupción de infinidad de nuevos conceptos científicos» que influyen en la vigencia de la propia Ley ${ }^{8}$.

Sin embargo, no cabe deducir que el sistema de la teoría del delito deba ser modificado "con calzador" para ajustarlo a los desafíos de la criminalidad moderna cada vez que el legislador así lo necesite por algún motivo puramente contingente. Seguramente, con una reflexión más profunda del legislador al abordar temas como éste o similares, se podría haber encontrado un sistema propio de responsabilidad administrativa fuerte (fuera del derecho penal de preferencia) para las personas jurídicas en vez de forzar algunas categorías de la teoría del delito ${ }^{9}$. De todas formas, para bien o para mal, si existe una norma vigente y, llegado el momento, el juez penal no podrá sino por mandato legal aplicar la Ley y (si corresponde) sancionar penalmente a una empresa con las penas que señalan ${ }^{10 .}$

\footnotetext{
${ }^{5}$ Alguna de las principales críticas que se plantea a la responsabilidad penal de la persona jurídica están las cuestiones relativas a su capacidad de acción, a la existencia de culpabilidad y al sentido de la pena impuesta a un ente colectivo. Véase al respecto VAN WEEZEL, "Contra la responsabilidad penal de las personas jurídicas", Política Criminal, vol. 5, n 9 (2010), pp. pp. 116 y ss.; RoBles Planas, "Pena y persona jurídica: crítica del artículo 31 bis CP”, Diario La Ley, 2011, pp. pp. 2 y ss.

${ }^{6}$ En este sentido aparece el brillante artículo de Lampe sobre injusto de sistema y sistemas de injusto. Véase LAMPE ««Systemunrecht und Unrechtssysteme, $Z S t W, \mathrm{n}^{\circ} 106,1994$, pp. 683 y ss.

${ }^{7}$ GRACIA MARTIN, Luis, «Crítica de las modernas construcciones de una mal llamada responsabilidad penal de la persona jurídica", Revista electrónica de ciencia penal y criminología, 2016, p. 73.

${ }^{8}$ SCHMITT, Carl, Posiciones ante el derecho, Madrid: Editorial Tecnos, 2015, p. 23

${ }^{9}$ En este sentido parece ir la propuesta de SILVA SÁNCHEZ, Jesús, «La responsabilidad penal de las personas jurídicas en derecho español», Comunicaciones en Propiedad Industrial y Derecho de la Competencia, $\mathrm{n}^{\circ} 65$ (Enero-Abril 2012), p. 5.

10 Un posible camino aun no explorado en la práctica es la solicitud de inaplicabilidad por inconstitucionalidad del art. 3 de la Ley 20.393 por vulnerar el principio de culpabilidad de las penas que estaría presente en la Constitución Política.
} 
Polit. crim. Vol. 13, № 26 (Diciembre 2018) Art. 10, pp. 1027-1054.

[http://www.politicacriminal.cl/Vol_13/n_26/Vol13N26A10.pdf]

Por otra parte, las críticas a una responsabilidad propiamente penal de las personas jurídicas se basan principalmente en la ausencia y fricción con los elementos y presupuestos básicos elaborados por la teoría del delito que deben concurrir en todo sujeto a quien se le atribuye responsabilidad penal. Estos presupuestos a los que nos referimos son aquellos que ha ido elaborando la moderna ciencia jurídico-penal durante los últimos doscientos años ${ }^{11}$.

En efecto, entre los principales presupuestos que ha elaborado la dogmática penal para asignar responsabilidad penal se encuentran la capacidad de acción y la culpabilidad de la persona a quien se le atribuye la realización de la conducta típica. De ahí que exista un amplio y generalizado consenso en señalar que el delito es una acción humana típica, antijurídica y culpable ${ }^{12}$. En este sentido, la definición dominante de delito parte por exigir una conducta humana, la cual debe realizar lo dispuesto un tipo penal ${ }^{13}$. En segundo lugar, y desde la formulación normativa de culpabilidad que plantearan Frank y Goldschmidt, el responsable de la realización de una acción típica debe ser susceptible de un reproche personal $^{14}$. Dicho juicio de reproche se conoce actualmente como culpabilidad ${ }^{15}$.

En relación con el último punto, la culpabilidad ha sido comprendida desde sus inicios como una garantía al exigir -para el reproche penal- que el autor a quien se hará responsable no hubiese podido evitar el delito o actuar de otro modo de manera tal que al no concurrir la libertad del sujeto no es posible realizar dicho reproche ${ }^{16}$. En otras palabras, la culpabilidad se concibió como una garantía para la persona frente al poder del Estado de imponer una pena cuya máxima se conoce bajo el lema nulla poena sine culpa.

El tema no es en absoluto una cuestión de mera discusión dogmática sin consecuencias directas en la práctica. Si se reflexiona sobre ello, la culpabilidad entendida como principio, consagra que sólo se puede imponer una pena al sujeto a quien le (pre) suponemos una libertad de actuación. El principio de culpabilidad parte de la base de la existencia de un libre albedrío por parte del sujeto a quien se hace responsable, pues se señala que sólo se es culpable quien pudiendo actuar de otro modo (quien siendo libre) decidió actuar de manera contraria al derecho ${ }^{17}$.

\footnotetext{
${ }^{11}$ Fundamental para el origen del derecho penal moderno fueron Cesare Beccaria en Italia y Paul Anselm von Feuerbach en Alemania. En especial con este último autor de quien podría afirmarse que fundó la dogmática penal moderna.

${ }^{12}$ ROXIN, Claus, Derecho penal. Parte general, t. I, 1997, p. 193; JESCHECK/WEIGEND, Lerhbuch des Strafrecht. Allgemeiner Teil, $5^{\text {a }}$ ed., 1996, §7/1, p. 50; CURY URZÚA Enrique, Derecho Penal. Parte general, $10^{\mathrm{a}}$ ed., 2011, p. 240.

${ }^{13}$ HEINRICH, Bern, Strafrecht. Allgemeiner Teil, $4^{\mathrm{a}}$ ed., 2014, p. 38; CURY URZÚA, Derecho Penal, cit. ${ }^{\circ}$ 13, p. 244.

${ }^{14}$ Véase la traducción de la obra de este último autor en GOLDSCHMIDT, La concepción normativa de la culpabilidad, B de F: Montevideo, 2002, p. 83 y ss.; FRANK, «Über den Aufbau des Schuldbegriffs», FS der Gießener Juristenfakültat zum 300 jährigen Bestehen der Universität Gießen, 1907.

${ }^{15}$ CURY URZÚA, Enrique, Derecho Penal, cit. ${ }^{\circ}$ 13, p. 385; GARRIDO MONTT, Mario, Derecho penal. Parte general, t. II, 1997, p. 196.

${ }^{16}$ Cfr. COUSO SALAS, Jaime, Fundamentos del derecho penal de culpabilidad, Valencia: Tirant lo Blanch, 2006, p. 557.

${ }^{17}$ En este sentido por todos JESCHECK Hanz-Heinrich /WEIGEND Thomas, Lerhbuch des Strafrecht. Allgemeiner Teil, $5^{\text {a }}$ ed., Berlin: Duncker \& Humblot, 1996, §7/I, p. 407.
} 
NAVAS, Iván; JAAR, Antonia. "La responsabilidad penal de las personas jurídicas en la jurisprudencia chilena".

Evidentemente el punto es controvertido frente a una persona como la jurídica que no actúa por sí misma, ni de quien se (pre) supone que es libre, sino que quienes actúan son las personas físicas en nombre de la persona jurídica. Hasta ahora, la discusión en la doctrina penal chilena sobre este punto es incipiente pero presenta algunas propuestas interesantes que analizar. Sumado a ello, también puede observarse, tímidamente un desarrollo en el derecho administrativo sancionador en su relación con el derecho penal a propósito de los principios como el de culpabilidad ${ }^{18}$. En términos generales se puede afirmar que la elaboración doctrinal tanto de la culpabilidad de las personas jurídicas como en general de la Ley 20.393 está en pleno desarrollo.

A nivel jurisprudencial tanto en la Corte Suprema como en el Tribunal Constitucional es posible encontrar opiniones que claramente plantean una diferencia entre ilícitos administrativos e ilícitos penales. Ello tiene como consecuencia distinguir las exigencias de las garantías frente a la imposición de sanciones del ámbito administrativo sancionador como del penal. Esta es la dirección que ha tomado al Corte Suprema cuando distingue cualitativamente entre injusto administrativo e injusto penal, diferenciando respectivamente ciertas exigencias en relación con las garantías que derivan de principios como el de culpabilidad. Así, esta distinción puede observarse en resoluciones de la Corte Suprema donde ha señalado que "los ilícitos administrativos importan un injusto de significación ético-social reducida, por lo que la imposición de sanciones en este ámbito no requiere de garantías tan severas como las que rodean a la sanción penal". Esto explicaría, a juicio de Cordero, por qué en materia administrativa el principio de culpabilidad no requiere la concurrencia de elementos subjetivos ${ }^{19}$.

Si bien es cierto que el Tribunal Constitucional ha declarado expresamente que la sanción administrativa y la penal son parte de un único ius puniendi estatal, el mismo órgano señala que las sanciones administrativas y las penales difieren en algunos aspectos y han de estar sujetas al mismo estatuto constitucional "pero con matices" 20 . En este contexto, el presente trabajo centra la atención en la interpretación que hacen los tribunales de la responsabilidad penal de las personas jurídicas en los casos que hasta ahora han llegado a sede judicial en Chile. No obstante, cabe advertir que, debido a la restricción de delitos por los cuales se puede hacer responsable a una persona jurídica, la aplicación de la Ley 20.393 es relativamente escasa. A pesar de esta escasez jurisprudencial, no por eso la aplicación de la Ley no deja de estar exenta de importantes problemas dogmáticos e interpretativos en los siete años que tiene de vigencia. Problemas que, por cierto, merecen total atención por parte de la doctrina.

\footnotetext{
${ }^{18}$ Véase al respecto CORDERO QUINZACARA Eduardo, «El derecho administrativo sancionador y su relación con el derecho penal», Revista de Derecho de Valdivia, n 2, 2012, pp. 131-157. En materia penal véase infra.

${ }^{19}$ CORDERO VEGA, Luis, Casos destacados de derecho administrativo, Santiago: Thomson Reuters, 2015, t. III, 6.3 .

${ }^{20}$ STC Rol 479 de fecha 08.08.2006. Recurso de inaplicabilidad por inconstitucionalidad. Ministro redactor: Jorge Correa Sutil.
} 
Polit. crim. Vol. 13, № 26 (Diciembre 2018) Art. 10, pp. 1027-1054.

[http://www.politicacriminal.cl/Vol_13/n_26/Vol13N26A10.pdf]

Para una exposición ordenada, en primer lugar, se hará una mención de los presupuestos de atribución de responsabilidad penal a la persona jurídica en el ordenamiento jurídico chileno. Con base en ellos se analizará la jurisprudencia que hasta la fecha se ha pronunciado sobre la responsabilidad penal de las personas jurídicas. Se pondrá énfasis en analizar si el principio de culpabilidad ha sido invocado y cómo ha sido su tratamiento por parte de los tribunales. Sin embargo, cabe resaltar al respecto algunos casos particulares en que este principio es invocado para absolver a la persona jurídica ${ }^{21}$. Por último, en el presente trabajo se analizará en específico las penas que se han aplicado.

Con el propósito de facilitar la lectura, las sentencias que existen sobre la materia en la jurisprudencia son las siguientes:

- Caso Maggi: Sentencia condenatoria dictada el día 14 de abril de 2014, causa caratulada "Fisco de Chile con Eadez", RIT No 1104-2011, RUC No 1000854916-3, por Juzgado de Garantía de Chillán, en contra de Sociedad Aridos Maggi Limitada por el delito de cohecho. Se interpuso recurso de apelación el cual se tramitó ante la Corte de Apelaciones de Chillán bajo el RIT No 105-2014.

- Caso Ceresita: Suspensión condicional del procedimiento, en contra de Industrias Ceresita S.A., causa caratulada "Ministerio Público con Reyes", RIT 157-2012, RUC 1101272897-4 del Tercer Juzgado de Garantía de Santiago, por el delito de cohecho ${ }^{22}$.

- Caso Colbún: Sentencia condenatoria dictada el día 12 de agosto de 2013, causa caratulada "Ministerio Público con Rojas", RIT No 9211-2012, RUC No 1201092968-5, por el Juzgado de Garantía de Talca, en contra de Salmones Colbún Limitada y Servicios Agrícolas Mecanizados Limitada por el delito de cohecho.

- Caso Asevertrans: Sentencia absolutoria dictada el día 2 de junio de 2015, causa caratulada "Consejo de Defensa del Estado con Asevertrans Limitada", RIT N ${ }^{\circ}$ 332014, RUC No 1100770074-3, por el Tribunal De Juicio Oral en lo Penal de Arica, en la cual se acusa a la persona jurídica Asevertrans Limitada por el delito de cohecho para luego absolverla.

- Caso Pehuenche: Sentencia condenatoria dictada el día 19 de agosto de 2015, causa caratulada "Ilustre Municipalidad de Santiago con Droguett", RIT No 11862-2014, RUC N $N^{\circ}$ 1400129785-7, por el $7^{\circ}$ Juzgado de Garantía de Santiago, en contra de Empresa Constructora Pehuenche por el delito de cohecho.

- Caso Universidad del Mar: Sentencia condenatoria dictada el día 2 de junio de 2016, causa caratulada "Ministerio Público con Luis Eugenio Díaz", RIT No 4799-2012, RUC $\mathrm{N}^{\mathrm{o}}$ 1200084351-0, por el $8^{\circ}$ Juzgado de Garantía de Santiago, en contra de La Universidad del Mar por el delito de cohecho.

\section{Presupuestos para la atribución de responsabilidad penal según la ley $\mathbf{N}^{0} \mathbf{2 0 . 3 9 3}$.}

\subsection{Requisitos}

\footnotetext{
${ }^{21}$ Véase en concreto el Caso Asevertrans.

${ }^{22}$ No consta la fecha exacta en la que se acordó la suspensión condicional del procedimiento en el documento disponible en el poder judicial.
} 
NAVAS, Iván; JAAR, Antonia. "La responsabilidad penal de las personas jurídicas en la jurisprudencia chilena".

Primero, es importante situar esta normativa dentro de los dos grandes modelos legislativos de responsabilidad penal de la persona jurídica. Por una parte, está el modelo de responsabilidad derivada o modelo de responsabilidad por atribución del hecho de otro (modelo heterónomo). Dicho modelo se caracteriza por la trasferencia de la responsabilidad penal de los sujetos miembros de la organización a la persona jurídica misma, en virtud de algún criterio que permite este traspaso ${ }^{23}$. Por otro lado, un segundo modelo de responsabilidad penal de la persona jurídica es el modelo de la responsabilidad autónoma u originaria, conocido también como modelo de responsabilidad por el hecho propio. En éste modelo se hace responsable a la persona jurídica por un hecho que le compete a ella, el cual generalmente consiste en un defecto de organización que permite o contribuye a la realización de conductas delictivas por parte de las personas físicas que actúan en su nombre ${ }^{24}$.

En este contexto, la doctrina chilena parece sumarse a la opinión de que el modelo adoptado por la legislación es el denominado modelo mixto. Ya en un inicio cuando la Ley era solo un proyecto Matus Acuña destacaba que por un lado no se establecía una atribución directa a las personas jurídicas por hechos cometidos por particulares, y por otro no establecía una responsabilidad autónoma de ellas porque se comprende que los entes colectivos no "se gobiernan con total autonomía" 25 . Ya siendo Ley vigente Ley $N^{\circ}$ 20.393, Hernández Basualto considera que la regulación chilena establece un modelo atenuado de responsabilidad derivada ya que exige conexión entre el hecho de la persona natural y la persona jurídica, pero exige también que la persona jurídica haya contribuido con un hecho propio a la comisión del delito, siendo éste el llamado "defecto de organización" $"$. En la misma línea, Bofill postula que el sistema consagrado en la Ley $\mathrm{N}^{\circ} 20.393$ es un sistema mixto. En concreto, este último autor destaca que cuando se cometen delitos en el interior de la empresa, la persona jurídica puede defenderse de la imputación a causa de la comisión del delito de la persona natural, alegando que ella se organizó adecuadamente, en los términos que la ley le exige organizarse. Es decir, puede alegar en su defensa que el delito base se encuentra en el ámbito exclusivo de responsabilidad de la persona natural y que, en lo que respecta a su propio ámbito de responsabilidad, no hay infracción de deber ni cumplimiento de los requisitos de imputación penal ${ }^{27}$.

Ahora bien, los requisitos de la responsabilidad penal de la persona jurídica, conforme al artículo $3^{\circ}$ de la ley, son los siguientes:

- Que el delito haya sido cometido por los dueños, controladores, responsables, ejecutivos principales, representantes o por quienes realicen actividades de administración y supervisión. Además, responderán cuando el delito se haya cometido por personas

\footnotetext{
${ }^{23}$ GARCÍA CAVERO, Percy, "Esbozo de un modelo de atribución de responsabilidad penal de las personas jurídicas", Revista de Estudios de la Justicia, No 16, p. 59.

${ }^{24}$ GARCÍA CAVERO, "Esbozo", cit. nota n ${ }^{\circ} 23$, p. 59.

${ }^{25}$ MATUS ACUÑA, Jean Pierre, "Informe sobre el proyecto de ley que establece la responsabilidad legal de las personas jurídicas en los delitos de lavado de activos, financiamiento del terrorismo y delitos de cohecho que indica, ensaje no 018-357”, Revista Ius et Praxis, vol. 15, núm 2, 2009, p. 295.

${ }^{26}$ HERNÁNDEZ BASUALTO, Héctor, "La introducción de la responsabilidad penal de las personas jurídicas en Chile", Política Criminal, Vol. 5, N 9, p. 217.

${ }^{27}$ BOFILL GENZSCH, Jorge, "Estructuras de imputación y prevención de delitos al interior de la persona jurídica”, en WILENMANN VON BERHATH, Javier (coord.), Gobiernos Corporativos, Aspectos esenciales de las reformas a su regulación, Santiago, Universidad Adolfo Ibáñez, 2011, p. 184.
} 
Polit. crim. Vol. 13, № 26 (Diciembre 2018) Art. 10, pp. 1027-1054.

[http://www.politicacriminal.cl/Vol_13/n_26/Vol13N26A10.pdf]

naturales que se encuentren bajo dirección o supervisión directa de alguno de los sujetos acabados de mencionar.

- Que los delitos hayan sido cometidos directa e inmediatamente en interés de la persona jurídica o en su provecho. Sin perjuicio de ello, las personas jurídicas no serán responsables en los casos que las personas naturales indicadas en los incisos anteriores, hubieren cometido el delito exclusivamente en ventaja propia o a favor de un tercero.

- Que la comisión del delito sea consecuencia del incumplimiento, por parte de la persona jurídica, de los deberes de dirección y supervisión.

\subsection{Aplicación de los requisitos legales por la jurisprudencia chilena.}

El desafío para los tribunales tanto en Chile como en otros países es mayúsculo cuando se trata de aplicar un derecho penal que ha sido elaborado a base de una persona física como sujeto de imputación. La jurisprudencia española, por ejemplo, ya ha dado algunos pasos en las sentencias sobre el tema ${ }^{28}$. Así, por ejemplo, ha dejado claro que cualquier pronunciamiento condenatorio de las personas jurídicas debe estar basado en los principios irrenunciables que informan el derecho penal ${ }^{29}$. Este pronunciamiento es clave para entender que el desafío no es configurar una nueva teoría del delito o un nuevo derecho penal para las personas jurídicas, sino que pasa por una nueva comprensión conceptual que permita dar cabida a la persona jurídica en el derecho penal.

En los siguientes párrafos se pretende dar a conocer cómo se ha invocado, fundamentado y aplicado los requisitos de la responsabilidad penal de la persona jurídica por los tribunales chilenos en aquellos casos que ha debido conocer del asunto.

\subsubsection{Primer requisito: la vinculación de la persona física con la jurídica}

En general, en la jurisprudencia se parte por verificar el vínculo entre las personas naturales que ejecutan el delito con la persona jurídica. Si se observa el panorama jurisprudencial, la vinculación de las personas físicas con la jurídica es el siguiente:

- Caso Maggi: (i) administrador de Áridos Maggi Limitada; y (ii) gerente general y representante legal de la misma empresa.

- Caso Ceresita: gerente de Recursos Humanos de Ceresita S.A.

- Caso Colbún: (i) socio, propietario y representante legal de Salmones Colbún Limitada; (ii) socio, propietario y representante legal de Sociedad Agrícola Mecanizados

\footnotetext{
${ }^{28}$ Véase las siguientes sentencias a personas jurídicas dictadas por el Tribunal Supremo Español: TS, Sala Segunda, de lo Penal, S 668/2017, 11 Oct. 2017 (Rec. 1625/2016); TS, Sala Segunda, de lo Penal, S 583/2017, 19 Jul. 2017 (Rec. 1813/2016); TS, Sala Segunda, de lo Penal, S 455/2017, 21 Jun. 2017 (Rec. 1447/2016); TS, Sala Segunda, de lo Penal, S 121/2017, 23 Feb. 2017 (Rec. 1916/2016); TS, Sala Segunda, de lo Penal, S 31/2017, 26 Ene. 2017 (Rec. 1177/2016); TS, Sala Segunda, de lo Penal, S 744/2016, 6 Oct. 2016 (Rec. 2299/2015); TS, Sala Segunda, de lo Penal, S 516/2016, 13 Jun. 2016 (Rec. 1765/2015); TS, Sala Segunda, de lo Penal, S 221/2016, 16 Mar. 2016 (Rec. 1535/2015); TS, Sala Segunda, de lo Penal, S 154/2016, 29 Feb. 2016 (Rec. 10011/2015); TS, Sala Segunda, de lo Penal, S 514/2015, 2 Sep. 2015 (Rec. $111 / 2015)$.

${ }^{29}$ STS 514/2015, de 2 de septiembre de 2015.
} 
NAVAS, Iván; JAAR, Antonia. "La responsabilidad penal de las personas jurídicas en la jurisprudencia chilena".

Limitada; (iii) gerente comercial de Salmones Colbún Limitada: y (iv) asesor legal de la misma empresa.

- Caso Asevertrans: dueño y representante legal de Asevertrans Limitada.

- Caso Pehuenche: representante legal y socio de Constructora Pehuenche Limitada.

- Caso Universidad del Mar: rector de la Universidad del Mar.

Ahora bien, para dar por cumplido este requisito los tribunales no se detienen a analizar si la persona natural realiza efectivamente actividades de administración y supervisión, sino que hasta ahora la jurisprudencia ha considerado en los principales casos como suficiente que la persona física ostente un cargo formal en el que, por regla general, debería realizar este tipo de actividades.

En el caso Asevertrans se presenta una problemática relativa a este punto. La empresa tenía como socios a R.O. G.G. y a E.A. Sin embargo, se señaló que en los hechos la empresa era dirigida por J.F. Aquí resulta interesante determinar bajo qué calificación de las enumeradas en el art. 3 de la Ley 20.393 quedan abarcados aquellas personas físicas como J.F. en el caso Asevertrans. A primera vista, la vinculación de quienes dirigen fácticamente la empresa es que estos realizaban actividades de administración y supervisión, es decir, en estos casos surge la figura del denominado administrador de hecho de la persona jurídica. El administrador de hecho es aquella persona que no teniendo una vinculación formal con la empresa debido a que no ha sido formalmente nombrada o habiéndolo sido, se produce una ineficacia civil de su nombramiento, ha asumido fáctica y materialmente las funciones de administración debido a una asunción de hecho por el consentimiento de los propios $\operatorname{socios}^{30}$. A fin de determinar materialmente el alcance de la descripción de la ley cabe sostener que estamos frente a un administrador de hecho cuando una persona ha asumido en los términos descritos ya sea toda de toda la gestión de la empresa o también de alguna parte de ella. Ahora bien, el administrador de hecho no tiene que administrar todas las actividades de la persona jurídica para estar comprendido en el art. 3 de la señalada Ley, sino que basta con que realice algunas de ellas. Como criterio restrictivo operará que haya cometido el delito directa o indirectamente en interés o provecho de la persona jurídica.

Al observar el resto de casos que comprenden la jurisprudencia de la materia, sólo en el denominado Caso Colbún podría quedar una duda razonable de si la persona realmente pertenece al círculo de personas físicas que señala la ley para arrastrar la responsabilidad penal de la empresa. En efecto, en dicho caso el imputado era estudiante de Derecho y tenía el cargo de asesor legal actuando, en opinión del tribunal "encomendado por los Sres. JIC y MIC, y con el patrocinio del abogado $I G O^{31}$. Ante tal situación, parece difícil afirmar que el imputado realice verdaderas funciones de administración y supervisión de la empresa como lo exige la ley. Sin embargo, el tribunal no hace referencia a éste punto, sino que da por hecho (presume) que el imputado realizaba funciones de dirección en la empresa. Por último, en el caso Maggi, no se encuentra ninguna referencia a la condición jurídica y vinculación de la persona física que comete el delito con la persona jurídica.

\footnotetext{
${ }^{30}$ GARCÍA CAVERO, Percy, La responsabilidad penal del administrador de hecho de la empresa: Criterios de imputación, Barcelona: Bosch, 1999, pp. 116 y ss.

${ }^{31}$ Ministerio Público con Rojas (2013).
} 
Polit. crim. Vol. 13, No 26 (Diciembre 2018) Art. 10, pp. 1027-1054.

[http://www.politicacriminal.cl/Vol_13/n_26/Vol13N26A10.pdf]

\subsubsection{Segundo requisito: el interés directo e inmediato de la persona jurídica}

$\mathrm{Al}$ igual que en la mayoría de los ordenamientos, el delito cometido por la persona física debe ir en provecho de la persona jurídica. La Ley 20.393 exige que el delito sea cometido por la persona física «directa e inmediatamente en interés» de la persona jurídica o «para su provecho».

En atención a la redacción utilizada por el legislador, algunos autores consideran se trata de una exigencia subjetiva ${ }^{32}$. Sin embargo, este criterio debería entenderse en términos objetivos sin considerar a las intenciones que perseguían los sujetos individuales, sino si efectivamente la persona se vio beneficiada por el delito cometido ${ }^{33}$.

En efecto, el interés directo de la persona jurídica debe ser objetivo y no depender de la intención que tenía el sujeto para involucrar a la empresa. De lo contrario, la interpretación de este requisito basado en el ánimo de la persona física sería incontrolable afectando la seguridad jurídica y a su prueba. Por otro lado, si bien la ley habla de interés «directo» no parece claro que deban quedar excluidos, en principio, los casos en que no se trate únicamente un beneficio monetario cuantitativo, sino que pueden comprenderse casos que de igual forma representa un beneficio. Así, por ejemplo, como una importante mejora de la imagen corporativa o reputación social que implique, entre otros, una ganancia en prestigio de la marca. Lo mismo cabe afirmar respecto a casos en que el provecho venga dado por la evitación de un perjuicio económico o ahorre de costes significativos para la empresa ${ }^{34}$.

En relación con la aplicación de este requisito en la jurisprudencia chilena, puede observarse que en la mayoría de los casos los tribunales afirman la existencia de este requisito sin traducir tal beneficio en un valor concreto o sin explicar tampoco cómo obtiene interés o provecho la persona jurídica. En efecto, no deja de sorprender que, por ejemplo, en el Caso Maggi, la sentencia no hace referencia alguna a este requisito. En relación con esta exigencia, a excepción del caso Maggi, la jurisprudencia se ha pronunciado en el siguiente sentido:

En la formalización del Caso Ceresita, el Ministerio Público lo plantea de la siguiente forma:

"La imputada V.C cometió dicho delito en interés directo e inmediato de Ceresita S.A. [...] a saber, que Ceresita S.A. pudiera mantener su planta de Recoleta en funcionamiento, a pesar de no contar el certificado de recepción final de obras, ni autorización sanitaria pertinente de la SEREMI de Salud, ni patente comercial, y en

\footnotetext{
${ }^{32}$ Así se desprende en HERNÁNDEZ BASUALTO, "La introducción”, cit. nota n 28, p. 221.

${ }^{33}$ FEIJOO SÁNCHEZ, Bernardo, «Las características básicas de la responsabilidad penal de las personas jurídicas en el Código Penal español», en BAJO FERNÁNDEZ/ FEIJOO SÁNCHEZ/ GÓMEZ-JARA, ed., Tratado de responsabilidad penal de las personas jurídicas, Navarra, Civitas, 2012, p. 102.

${ }^{34}$ En este sentido ZUGALDÍA ESPINAR, José Miguel, La responsabilidad criminal de las personas jurídicas, de los entes sin personalidad y de sus directivos, 2013, p. 77.
} 
NAVAS, Iván; JAAR, Antonia. "La responsabilidad penal de las personas jurídicas en la jurisprudencia chilena".

circunstancias que el plan regulador de la comuna de Recoleta prohíbe el giro de Industria en la zona en que se encuentra el inmueble, entre otras irregularidades" ${ }^{35}$.

De la misma forma, en el Caso Colbún, el tribunal considera que el delito realizado beneficia a la persona jurídica en cuanto "permitió un aumento patrimonial de los activos de cada empresa, mediante la incorporación fraudulenta de derechos de aguas en predios de su propiedad ubicados en la región de Maule equivalente a 3300 litros por segundo"36.

En el Caso Asevertrans, el tribunal señala que "la acción de soborno de Frías era para obtener la renovación de la PP 9/2009, es decir, una acción que iba en directo beneficio de su empresa Asevertrans". En relación con este caso, el tribunal observa difícil poder distinguir la actuación de una y otra persona, ya que en el fondo es imposible diferenciar el actuar de la persona natural y el de la persona jurídica:

"En efecto, la conducta desplegada por JFE de sobornar a funcionarios públicos iba en directo beneficio no solo de su empresa, sino que de él directamente, lo que hace que la existencia o no de cualquier modelo de prevención en la especie es inocuo, ya que al ser Asevertrans una empresa unipersonal, no hay acciones que puedan diferenciar la conducta de JFE con la de la empresa, ya que en la práctica es la persona natural la que actúa o dicho de otra forma, la persona natural y jurídica se confunden en el ejercicio de su vida comercial" ${ }^{\prime 37}$.

Como se puede apreciar, parece que en estos casos ningún modelo de prevención podría tener efecto si la persona jurídica está compuesta por una única persona física.

Por su parte, en el Caso Pehuenche, el tribunal señala que el interés producido para la empresa es el siguiente:

Durante la ejecución del contrato de pavimentación, el municipio dejó de cursar a la empresa Constructora Pehuenche Limitada multas por un monto aproximado y total de \$188.472.735., y de no mediar las conductas desplegadas por el Subdirector de Pavimentación SDE, se hubiese puesto término al mismo por el incumplimiento ${ }^{38}$.

Finalmente, en el Caso Universidad del Mar el provecho tiene relación con el hecho de que al obtener la acreditación institucional, las universidades pueden recibir alumnos con beneficio CAE (Crédito con Aval del Estado). Ello tiene consecuencias financieras importantes para la institución ya que obtiene retornos seguros, aún respecto de alumnos de escasos recursos ${ }^{39}$. En esta sentencia, el tribunal sí especifica cuáles son los ingresos recibidos por la institución:

\footnotetext{
${ }^{35}$ CAÑAS ARANDA, Macarena, "Responsabilidad penal de las personas jurídicas, Suspensión condicional del procedimiento Industrias Ceresita S.A”, Revista Jurídica del Ministerio Público, No 55, 2013 , pp. 79-92.

${ }^{36}$ Ministerio Público con Rojas (2013).

${ }^{37}$ Consejo de Defensa del Estado con Asevertrans Limitada (2015).

${ }^{38}$ Ilustre Municipalidad de Santiago con Droguett (2015).

${ }^{39}$ Ministerio Público con Luis Eugenio Díaz (2016).
} 
Polit. crim. Vol. 13, No 26 (Diciembre 2018) Art. 10, pp. 1027-1054.

[http://www.politicacriminal.cl/Vol_13/n_26/Vol13N26A10.pdf]

Dichas conductas fueron ejecutadas en directo interés y provecho de la Universidad del Mar, por cuanto su rector, autoridad máxima de la institución, consintió en dar un beneficio económico a un funcionario público a cambio de obtener la acreditación institucional que en definitiva le reportó un ingreso por concepto de Crédito con Aval del estado (CAE) de los siguientes montos:\$2.018.242.352 con fecha 23.09.2011; $\$ 1.540 .000 .000$ con fecha 23.09.2011; \$1.319.398.078 con fecha 17.10.2012; $\$ 1.487 .960 .405$ con fecha 16.11.2012 y montos totales durante el año 2013 superiores a los tres mil millones de pesos ${ }^{40}$.

1.2.3 Tercer requisito: el incumplimiento de los deberes de dirección y supervisión por parte de la persona jurídica

Aquí encontramos uno de los requisitos más complejos de la responsabilidad de la persona jurídica que da origen al modelo mixto que sigue el ordenamiento jurídico chileno. En efecto, se trata de existencia de un delito cometido tanto por una persona física vinculada a la empresa, como de la existencia de un defecto de organización de la propia empresa que se refleja en el incumplimiento de deberes de dirección y supervisión que facilitan la comisión del delito respecto a las personas físicas.

El denominado defecto de organización puede comprenderse como un déficit de auto regulación permanente de la persona jurídica ${ }^{41}$. Se trata de una omisión de medidas preventivas necesarias para evitar que posteriormente se cometan delitos dentro del ejercicio de su actividad. Algunos autores la asimilan a la estructura de la actio libera in causa en el sentido de que la culpabilidad no está presente en el momento de realización del hecho por parte de la persona física, sino que se recurre a un momento anterior donde no se tomaron medidas por parte de la persona jurídica que hubiesen evitado la comisión del hecho $^{42}$. Esta crítica tiene pleno sentido frente a las tesis que configuran la culpabilidad de la persona jurídica como una «culpabilidad duradera» y no aquella que sólo tiene que existir al momento del hecho ${ }^{43}$.

De acuerdo con la regulación chilena, el cumplimiento de los deberes de dirección y supervisión viene dado por el hecho de que la persona jurídica haya implementado con anterioridad a la comisión del delito por parte de la persona física un modelo de prevención con las características que exige en su art. 4. Sin embargo, el cumplimiento de los deberes de la empresa se puede llevar a cabo de otro modo distinto a cómo lo exige la ley, pues en el art. 4 se regula una forma de dar cumplimiento a los deberes de dirección y supervisión ${ }^{44}$. En otras palabras, no es obligación asumir un modelo de prevención como el señalado por la Ley en el art. 4, al menos dicho modelo es facultativo pero no obligatorio para las

\footnotetext{
${ }^{40}$ Ministerio Público con Luis Eugenio Díaz (2016).

${ }^{41}$ NIETO MARTIN, Adán, La responsabilidad penal de las personas jurídicas: Un modelo legislativo, 2008, pp. 324 y ss.

${ }^{42}$ Véase críticamente GRACIA MARTÍN, Luis, "Crítica de las modernas construcciones de una mal llamada responsabilidad penal de la persona jurídica”, Revista electrónica de ciencia penal y criminología, 2016, p. 18.

${ }^{43}$ HEINE, Die strafrechtliche Verantwortlichkeit von Unternehmen, pp. 278 y ss.

${ }^{44}$ De la misma opinión HERNÁNDEZ BASUALTO, «La introducción de la responsabilidad penal de las personas jurídicas en Chile» Política Criminal, Vol. 5, $\mathrm{N}^{\circ}$ 9, 2010, p. 225; van Weezel, «Contra la responsabilidad penal de las personas jurídicas», Política Criminal, Vol. 5, n 9, 2010, p. 138.
} 
NAVAS, Iván; JAAR, Antonia. "La responsabilidad penal de las personas jurídicas en la jurisprudencia chilena".

personas jurídicas que pretenden cumplir con sus deberes de dirección y supervisión. De lo contrario, condenar a una persona jurídica por no tener el modelo de prevención que se desprende de los requisitos previstos en la Ley 20.393 implica una presunción de culpabilidad que, en un derecho penal del hecho, no tiene cabida ${ }^{45}$.

En la práctica este tercer requisito presenta dos problemas: El primero tiene relación con el hecho de que el tribunal puede considerar que, por no haberse implementado un modelo de prevención de delitos, necesariamente se están incumplimiento los deberes de dirección y supervisión. Esto ocurre en el Caso Colbún:

\begin{abstract}
"Se razona de este modo toda vez que dicho ilícito fue cometido directa e inmediatamente en su interés o provecho por sus dueños y representantes y como consecuencia del incumplimiento de sus deberes de dirección y supervisión, los cuales no se consideran cumplidos toda vez que no se ha adoptado ni implementado un modelo de organización, administración y supervisión para prevenir delitos conforme al artículo 4 de la Ley 20.393, esto último acreditado mediante el Oficio $\mathrm{N}^{\mathrm{o}} 1.831 \mathrm{de}$ 28 de enero de 2013 de la Superintendencia de Valores y Seguros, a quien corresponde llevar el registro de las Entidades Certificadoras de Modelos de Prevención de Delitos que alude el artículo 4 de la Ley 20.293, las cuales deben remitir información anual sobre las personas jurídicas que certifiquen, que da cuenta que SALMONES COLBUN LTDA y SERVICIOS AGRÍCOLAS MECANIZADOS LTDA no figuran en la información remitida como personas jurídicas certificadas" ${ }^{\prime 6}$.
\end{abstract}

Esta forma de razonar del tribunal es problemática debido a que el artículo $3^{\circ}$ la Ley $\mathrm{N}^{\circ}$ 20.393 sólo establece una presunción a favor de la persona jurídica si es que ésta adoptó el modelo de prevención: "Se considerará que los deberes de dirección y supervisión se han cumplido cuando, con anterioridad a la comisión del delito, la persona jurídica hubiere adoptado e implementado modelos de organización, administración u supervisión para prevenir delitos". Por tanto, de la Ley no puede deducirse que el hecho de no adoptar el modelo de organización implica necesariamente que no se cumplieron los deberes de dirección y supervisión.

Por otro lado, hay un segundo problema que tiene relación con una falta de justificación y de prueba en algunas sentencias del hecho de que la empresa no contó con mecanismos para prevenir el delito. En los casos Pehuenche y Ceresita se usa la misma fórmula para referirse a este requisito:

"La comisión de delito en comento, fue consecuencia del incumplimiento de los deberes de dirección y supervisión de la persona jurídica imputada, esto es, empresa constructora Pehuenche Limitada, toda vez que, de acuerdo a los dispuesto en el artículo 3 de la Ley 20.393, esta sociedad no adoptó ni implementó, con anterioridad a los hechos, un modelo de prevención de delitos en los términos del artículo $\mathrm{n}^{\circ} 4$ de la misma ley, ni contó con mecanismos para prevenir la conducta de soborno antes descrita" ${ }^{47}$.

\footnotetext{
${ }^{45}$ Crítico con las presunciones en materia penal CURY URZUA cit. nota $n^{\circ} 13$, p. 345.

${ }^{46}$ Ministerio Público con Rojas (2013).

${ }^{47}$ Ministerio Público con Rojas (2013).
} 
Polit. crim. Vol. 13, No 26 (Diciembre 2018) Art. 10, pp. 1027-1054.

[http://www.politicacriminal.cl/Vol_13/n_26/Vol13N26A10.pdf]

En consecuencia, el tribunal, para afirmar que no se cumplieron los deberes de dirección y supervisión argumenta que no se implementó ningún modelo de prevención y que tampoco la empresa tenía mecanismos para evitar la comisión del delito. Sin embargo, en ninguna de las dos sentencias se justifica ni se prueba el hecho de que la empresa no contó con mecanismos para prevenir la comisión del delito. Al parecer no se estaría exigiendo que el Ministerio Público pruebe esta afirmación, y si es que se exigió, esto no quedó plasmada en la sentencia.

Por último, y con mucho más razonamiento y análisis del caso está la sentencia del Caso Universidad del Mar, no se limita a usar la fórmula tipo de las dos sentencias anteriores, sino que explica con mayor detalle por qué este requisito se verifica enumerando diversas medidas que la institución podría haber tomado y que no fueron implementadas:

"No se designaron en ninguna de ellas a un encargado de prevención u oficial de cumplimiento que estableciera método para la aplicación efectiva de un modelo y que realizara asimismo labores de supervisión y mejora. No se destinaron por parte de la Corporación recursos ni medios materiales para realizar labores de prevención ni capacitaciones para prevenir dicho ilícito, no se realizaron labores para identificar dentro de la corporación las actividades o procesos de la entidad en que se generaba o incrementaba el riesgo de la comisión del delito de soborno, especialmente en relación con la CNA y sus integrantes.[...] No se establecieron por dichas Corporaciones un sistema de denuncia o prosecución de responsabilidades para el caso de incumplimiento, ni un sistema de denuncias anónimas sobre posibles conductas contrarias a la probidad pública" ${ }^{98}$.

\section{Los principios limitadores del ius puniendi en la jurisprudencia penal de las personas jurídicas.}

3.1 Principio de culpabilidad y persona jurídica.

Al igual que la mayoría de los Códigos penales del entorno común, el Código penal chileno no contiene un concepto de culpabilidad y sólo aparecen regulados positivamente los presupuestos bajo los cuales un comportamiento típico y antijurídico no puede imputarse al autor, por ejemplo, por tratarse de un caso de un inimputable, de un menor de edad o por encontrarse en una situación de inexigibilidad de otra conducta (un caso de miedo insuperable). Ahora bien, frente al concepto negativo de culpabilidad, la doctrina y jurisprudencia sí han elaborado un concepto positivo donde el punto de partida consiste en que si el sujeto no ha sido libre a la hora de cometer el delito, no puede haber

\footnotetext{
${ }^{48}$ Ministerio Público con Luis Eugenio Díaz (2016).
} 
NAVAS, Iván; JAAR, Antonia. "La responsabilidad penal de las personas jurídicas en la jurisprudencia chilena".

culpabilidad $^{49}$.

Conforme a la idea dominante de la culpabilidad, cabe contrastar la aplicación de este principio y su contenido en los casos de imputación a las personas jurídicas. Sin embargo, realizar una aplicación en una persona jurídica de los requisitos de imputabilidad, exigibilidad de la conducta y conciencia de la ilicitud, tal como se conocen y aplican en la persona natural parece imposible. La dificultad de hacer este reproche personal a la persona jurídica se refleja en que en ninguno de los casos en estudio el tribunal hace referencia al principio de culpabilidad ni para referirse al concepto positivo de culpabilidad - a la existencia de una libertad de obrar-, ni para abordar la culpabilidad desde un concepto negativo -condiciones que deben concurrir en la persona para afirmar su culpabilidad-.

Ahora bien, esta aparente imposibilidad de exigirle a la persona jurídica la misma culpabilidad que se le exige a la persona natural no es una observación muy categórica. Un sector de la doctrina considera que la persona jurídica sí puede ser sujeto capaz de una imputación penal culpable siempre que se esté considerando un concepto de culpabilidad analógico a la culpabilidad de la persona natural ${ }^{50}$. Así, por ejemplo, se plantea por parte de la doctrina que la individualidad y socialidad que son necesarias para culpar a una persona natural deben tener sus equivalentes en la persona jurídica, para así poder aplicar el principio de culpabilidad en ella. En este sentido, se propone un significado de la individualidad para la persona jurídica: "puede llegarse a la conclusión de que el ente colectivo llega a alcanzar una individualidad cuando su complejidad organizativa permite una autorreferencialidad importante de la propia persona jurídica y el desarrollo de intereses societarios ajenos a los de sus órganos, representantes y socios ${ }^{, 51}$. En cuanto a la socialidad se señala lo siguiente:

"La persona jurídica no se presenta en este ámbito en un nivel social inferior a la persona natural, sino que actúa con las mismas facultades y capacidades de organización. Es titular igualmente del estatus de ciudadano, lo que otorga a sus actuaciones un sentido jurídico específico y justifica una respuesta social concreta (esto es, responsabilidad)" ${ }^{\prime 52}$.

La jurisprudencia se ha sumado al concepto positivo de la culpabilidad y a su fundamento radicado en la libertad como capacidad individual de actuar de otra manera. Así, el Tribunal Federal Alemán ha señalado que «la pena presupone culpabilidad entendida esta última como reprochabilidad. Con el juicio de desvalor de la culpabilidad se reprocha al autor que él no se haya comportado de modo adecuado a derecho, a pesar de que él pudo comportarse conforme a derecho» ${ }^{53}$.Por su parte el Tribunal Constitucional Chileno ha sostenido sobre

\footnotetext{
${ }^{49}$ Véase COUSO SALAS, Jaime, Fundamentos del derecho penal de la culpabilidad», 2006, pp. 559 y ss.

${ }^{50}$ GARCÍA CAVERO, cit. nota ${ }^{\circ}$ 24, p. 65; GÓMEZ-JARA, La culpabilidad de la empresa, Madrid: Marcial Pons, 2005, pp. 201 y ss.

${ }^{51}$ GARCÍA CAVERO, cit. nota $\mathrm{n}^{\circ}$ 24, p. 65; GÓMEZ-JARA, La culpabilidad de la empresa, Madrid: Marcial Pons, 2005, pp. 201 y ss.

52 GARCÍA CAVERO, cit. nota $\mathrm{n}^{\circ}$ 24, p. 65; GÓMEZ-JARA, La culpabilidad de la empresa, Madrid: Marcial Pons, 2005, pp. 201 y ss.

${ }^{53}$ BGHSt, 2, 194. Véase en KINDHÄUSER, Urs, «Culpabilidad jurídico-penal en el estado democrático de derecho», Revista de derecho, vol. 10, 2009, p. 138.
} 
Polit. crim. Vol. 13, № 26 (Diciembre 2018) Art. 10, pp. 1027-1054.

[http://www.politicacriminal.cl/Vol_13/n_26/Vol13N26A10.pdf]

la materia que «la culpabilidad es un presupuesto indispensable de la responsabilidad penal; que supone la posibilidad de obrar de otra forma y además la conciencia de ilicitud, sin poder presumirse de derecho el conocimiento de lo injusto» ${ }^{54}$.

En general, en la doctrina chilena el panorama sobre responsabilidad de las personas jurídicas y en especial sobre la culpabilidad está abierto. La discusión ha sido abordada recientemente primando las posturas que reconocen la existencia de una responsabilidad propiamente "penal". Sin embargo, dentro de estas posturas lo que difiere es por qué se hace responsable a la persona jurídica. Al respecto en la discusión chilena destacan, entre otras, las posturas de Mañalich, Collado González, Artaza Varela, Hernández Basualto y de Balmaceda Hoyos y Guerra Espinosa. Al respecto, se observa un esfuerzo por abordar los problemas a través de algunos planteamientos generales para sortear los obstáculos dogmáticos que encuentra la atribución de una responsabilidad estrictamente penal a un ente colectivo. En este intento cabe destacar el trabajo de Collado González, quien en una de las pocas monografías chilenas sobre la materia aborda sistemáticamente la mayoría de los puntos de discusión. Al respecto, este autor plantea que la responsabilidad penal de la empresa se estructura, en sede de tipicidad, como un tipo de intervención omisiva, es decir, sería un delito de omisión pura referido a la no implementación de un modelo de prevención de delitos. De ello se derivaría que esta omisión facilita o contribuye a la comisión activa de delitos por parte de los sujetos relacionados con la empresa. Sin embargo, es bastante difícil que la responsabilidad de la empresa se fundamente en una omisión pura por el hecho de que la implementación del modelo de prevención es meramente facultativa. En otras palabras, el deber que trasciende la norma de la cual emana la responsabilidad de la empresa no es un deber, sino una facultad. Partiendo de la premisa de que las omisiones penalmente relevantes contienen un deber que, una vez vigente, su cumplimiento no puede quedar al arbitrio del destinatario, entonces parece difícil que la responsabilidad penal de la empresa pueda estar estructurada como un delito de omisión pura.

Al respecto, en relación con la problemática específica de la culpabilidad, especial mención merece la opinión que fundamenta la culpabilidad de la persona jurídica en virtud de la responsabilidad por el carácter o por la conducción de su propia vida. La tesis de la responsabilidad de la persona jurídica basada en el carácter la propuso por primera vez y casi de forma paralela por Heine, por una parte, y Lampe, por otra. En resumidas cuentas, según esta tesis la culpabilidad de la empresa se debe o es la consecuencia de un carácter empresarial defectuoso que se mantiene a lo largo del tiempo y que no va referido a acciones específicas en un momento determinado, sino que guarda relación con la forma de ser de la corporación. En palabras de Lampe, la culpabilidad de la empresa consiste en que ella ha creado o mantenido ("cultivado") una filosofía criminógena. La culpabilidad de ella es consecuencia de su carácter defectuoso ${ }^{55}$.

Así, siguiendo la idea de la responsabilidad por el carácter, Mañalich sostiene que a la persona jurídica sí se le puede dirigir un reproche a su modo de ser, esto es, a su carácter,

\footnotetext{
${ }^{54}$ STC Rol 1584-09 de 17 de junio de 2010. La cursiva es nuestra.

${ }^{55}$ LAMPE, «Systemunrecht und Unrechtssysteme», ZStW, $\mathrm{n}^{\circ}$ 106, 1994, p. 732.
} 
NAVAS, Iván; JAAR, Antonia. "La responsabilidad penal de las personas jurídicas en la jurisprudencia chilena".

por ser éste no la base de su responsabilidad personal, sino su objeto ${ }^{56}$. Según este autor, el delito imputado a la persona jurídica es el reconocimiento o un síntoma del carácter defectuoso de ella ${ }^{57}$. En esta misma línea de argumentación se puede citar a Collado González quien ha señalado que el reproche hacia la persona jurídica va dirigido a su organización, esto es, a la forma en que dicha organización fue implementada ${ }^{58}$. Según él, la culpabilidad de una empresa se fundamenta en una conducción de la vida empresarial donde lo que se reprocha no es un hecho, sino que un estado de cosas u organización defectuosa ${ }^{59}$.

Un camino -legítimo y necesario por cierto- que han tomado algunos autores es recoger algunos planteamientos desde la discusión general del derecho comparado. Así, algunos autores como como Balmaceda Hoyos y Guerra Espinosa se adhieren al modelo constructivista que les permite hablar de un equivalente funcional para fundamentar la culpabilidad de las personas jurídicas ${ }^{60}$. Estos autores parten de la base de que el concepto de persona no es exclusivo de la persona físico-natural. Para este último se debe reservar el concepto de individuo. Así, persona es quien representa un rol en la sociedad al cual le es atribuido distintas competencias. De esta forma una persona jurídica es sujeto de atribución por un defecto de organización ya que, según Balmaceda Hoyos y Guerra Espinosa, ella sí posee una libertad de auto-determinación ${ }^{61}$.

Ahora bien, la problemática sobre la categoría de la culpabilidad -así como otras- en la aplicación sobre la persona jurídica no es solo un tema formal, sino de contenido material. En un sentido similar a la postura anterior y bajo la lógica de la teoría sistémica constructivista va la argumentación de Segovia Arancibia. En efecto, éste último autor reconoce este inconveniente de ajustar el concepto de culpabilidad individual que existe para la persona natural a la persona jurídica debido a la propia naturaleza conceptual. Señala acertadamente, que el contenido conceptual de culpabilidad individual-personal impide su traslado hacia un sujeto colectivo esencialmente por la diferente forma de intervención social de cada uno ${ }^{62}$. Según, el "modelo" adecuado es el de los sistemas sociales autopoiéticos formulado por el sociólogo Niklas Luhmann según el cual la persona jurídica es un sistema que tendría cualidades propias como autonomía, auto-administración, autoconducción y autoorganización que la haría independiente de los miembros que individualmente la conforma. Se trata de una tesis también de índole constructivista basada en la distinción personas e individuos.

\footnotetext{
${ }^{56}$ MAÑALICH, Juan Pablo, "Organización delictiva. Bases para su elaboración dogmática en el derecho penal chileno", Revista Chilena de Derecho, vol. 38 N$^{\circ}$ 2, (2011), p. 303.

${ }^{57}$ MAÑALICH, Juan Pablo, "Organización delictiva”, cit. nota n 41, p. 304.

${ }^{58}$ COLLADO GONZÁLEZ, Rafael, Empresas criminales, Santiago de Chile, Thomson Reuters, 2013, p. 107.

${ }^{59}$ COLLADO GONZÁLEZ, Rafael, Empresas criminales, cit. nota n ${ }^{\circ} 43$, p. 108.

${ }^{60}$ BALMACEDA HOYOS, Gustavo; GUERRA ESPINOSA, Rodrigo. Políticas de prevención de delitos en la empresa, Santiago de Chile, Thomson Reuter, 2014, p. 116 y ss.

${ }^{61}$ BALMACEDA HOYOS, Gustavo; GUERRA ESPINOSA, Rodrigo. Políticas de prevención, cit. nota $\mathrm{n}^{\circ}$ 58 , p. 117.

${ }^{62}$ SEGOVIA ARANCIBIA, Antonio, "Modelos de atribución de responsabilidad penal a las personas jurídica en la Ley 20.393", Revista Jurídica del Ministerio Público, N 43, junio 2010. p. 229.
} 
Polit. crim. Vol. 13, № 26 (Diciembre 2018) Art. 10, pp. 1027-1054.

[http://www.politicacriminal.cl/Vol_13/n_26/Vol13N26A10.pdf]

Como se observa, el concepto de defecto de organización ha sido acogido por parte importante de la doctrina chilena. Sin embargo, Artaza Varela se muestra crítico con este concepto como fundamento de la culpabilidad de la empresa. Según este autor, las tesis del defecto de organización de la empresa como causa que favorece la comisión del delito por parte de uno de los integrantes de la misma, no parece suficiente para imponer responsabilidad jurídico-penal y tampoco parece adecuada denominarla como «culpabilidad» de la empresa ${ }^{63}$. Para él, la culpabilidad por el defecto de organización se podría entender adecuadamente como la generación de un criterio de legitimidad para la imposición de responsabilidad jurídica basado en la equidad $[\ldots]^{64}$. Artaza Varela, señala que la idea del defecto de organización sigue tratándose de una imposición de responsabilidad jurídica pero con base en consideraciones muy diversas a la idea de la pena en sede jurídico-penal y a los criterios de legitimidad ${ }^{65}$. Lo que critica este autor es que el modelo del hecho propio a través del defecto de organización no respetaría el principio de personalidad de las penas que emana del principio de culpabilidad ${ }^{66}$. Junto con las manifestaciones del principio de culpabilidad (personalidad de las penas, responsabilidad subjetiva, responsabilidad por el hecho propio, etc.), para Artaza Varela las consideraciones que debieren tenerse en cuenta para una responsabilidad penal de la persona jurídica tienen como punto de partida la teoría de la organización empresarial. A partir de ella, este autor desarrolla un concepto de imputación subjetiva a la empresa que permita sostener, en primer lugar, que la empresa actúa en forma diferenciada de sus integrantes individuales y, en segundo, que la conducta de la empresa pueda ser considerada jurídico-penalmente relevante de cara a las normas jurídico-penales y a las reglas de conducta que se desprenden de ellas ${ }^{67}$.

Por otra parte, una opinión crítica con la existencia de una responsabilidad penal general de las personas jurídicas es la sostenida por Alex Van Weezel. Según este autor, con la existencia de la responsabilidad penal de las personas jurídicas vulnera tanto el contenido del principio de culpabilidad por el hecho como también la prohibición de non bis in ídem que emana de él. A tal punto que Van Weezel señala que una pena penal a una persona jurídica debe entenderse como una pena sin culpabilidad por el hecho, pues no se da una identidad personal (culpabilidad personal) entre quien comete el hecho y quien recibe la sanción $^{68}$. Al respecto sostiene que para producir efecto la pena debe heredarse a la empresa culpable, esté o no contenido en la persona jurídica que finalmente resulta sancionada. Así mismo, señala que la idea de que el delito de la persona natural opere como condición objetiva de punibilidad respecto a la persona jurídica implica un reconocimiento del carácter objetivo de la responsabilidad de ésta última. Ello, por cuanto parece reflejar que los elementos indispensables para fundar el reproche penal no necesitan ser imputados objetiva ni subjetivamente a la persona jurídica ${ }^{69}$. En virtud de lo anterior, Van Weezel

\footnotetext{
${ }^{63}$ ARTAZA VARELA Osvaldo, La empresa como sujeto de imputación de responsabilidad penal, Madrid: Marcial Pons, 2013, p. 170.

${ }^{64}$ ARTAZA VARELA, Osvaldo, “La empresa”, cit. nota ${ }^{\circ}$ 65, 2013, p. 170.

${ }^{65}$ ARTAZA VARELA, Osvaldo, "La empresa”, cit. nota ${ }^{\circ} 65,2013$, p. 170.

${ }^{66}$ ARTAZA VARELA, Osvaldo, “La empresa”, cit. nota ${ }^{\circ} 65,2013$, p. 172.

${ }^{67}$ ARTAZA VARELA, Osvaldo, “La empresa”, cit. nota ${ }^{\circ} 65,2013$, pp. 175 y ss.

${ }^{68}$ VAN WEEZEL, "Contra”, cit. nota ${ }^{\circ} 46$, p. 123

${ }^{69}$ VAN WEEZEL, “Contra”, cit. nota ${ }^{\circ} 46$, p. 122.
} 
NAVAS, Iván; JAAR, Antonia. "La responsabilidad penal de las personas jurídicas en la jurisprudencia chilena".

advierte que la Ley $\mathrm{N}^{\mathrm{o}} 20.393$ pone en riesgo la vigencia del principio de culpabilidad (o al menos la comprensión de él) como uno de los pilares del derecho penal chileno ${ }^{70}$.

Considerando entonces que la aplicación del principio de culpabilidad para imputar responsabilidad penal a la persona jurídica debiera hacerse usando un concepto analógico o equivalente de culpabilidad, cabe preguntarse cómo (si es que) los tribunales chilenos hacen referencia y con que alcance a la culpabilidad de las empresas que condenan. Lamentablemente, la respuesta no es muy alentadora. En ninguno de los casos en estudio el tribunal analiza si es que la persona jurídica tiene un sistema organizativo interno lo suficientemente complejo que permita hacerla auto-responsable por su actuar. Cabe destacar entonces que la jurisprudencia chilena, al condenar a las personas jurídicas, no ha hecho referencia alguna al principio de culpabilidad entendido como el mismo que se aplica a las personas naturales ni tampoco entendiéndolo como un concepto analógico de culpabilidad.

Esta situación es de suma gravedad para algunos autores, dentro de los cuales está GÓMEZJARA que insiste en la construcción de un concepto de culpabilidad jurídico-penal empresarial:

"Dicho clara y llanamente, este trabajo defiende la construcción de una culpabilidad jurídico-penal de la empresa debido a que en un "genuino" Derecho penal empresarial la culpabilidad se constituye en fundamento y límite de la imposición de un determinado tipo de sanciones -las penas- a la empresa y éstas son las únicas que contribuyen al completo restablecimiento comunicativo de la vigencia del ordenamiento jurídico"71.

En la jurisprudencia comparada, el Tribunal Supremo Español se ha pronunciado sobre el punto y entiende que la culpabilidad de la persona jurídica pasa por no haber adoptado medidas de prevención adecuadas para prevenir que las personas físicas que la integran cometieran los delitos que se le imputan. Así, expresamente ha señalado que "en el plano culpabilístico la responsabilidad de la persona jurídica se fundamenta en permitir o favorecer su comisión al haber eludido la adopción de medidas de prevención adecuadas" ${ }^{92}$. Esta jurisprudencia entiende que el delito cometido por la persona física ha sido posible o facilitado por la ausencia de una cultura de respeto al Derecho como fuente de inspiración de la actuación de su estructura organizativa e independiente de cada una de las personas físicas que la integran $^{73}$. Ahora bien, la cultura del respeto por el derecho -que representa en definitiva la culpabilidad del ente colectivo- exigiría la existencia real de modelos de prevención adecuados reveladores de una «cultura de cumplimiento» que persigue la norma penal en la persona jurídica. Por otro lado, en estos pronunciamientos se aprecia la exigencia del principio de culpabilidad a través del reproche por un hecho propio que sería, la no implementación de modelos de prevención que han facilitado

\footnotetext{
${ }^{70}$ VAN WEEZEL, “Contra”, cit. nota $\mathrm{n}^{\circ} 46, \mathrm{p} .137$.

${ }^{71}$ GÓMEZ-JARA, La culpabilidad, cit. nota $\mathrm{n}^{\circ}$ 54, p. 69 [destacado en el original].

${ }^{72}$ STS (Pleno) 154/2016, de 29 de febrero de 2016.

${ }^{73}$ STS (Pleno) 154/2016, de 29 de febrero de 2016. La cursiva es nuestra.
} 
Polit. crim. Vol. 13, No 26 (Diciembre 2018) Art. 10, pp. 1027-1054.

[http://www.politicacriminal.cl/Vol_13/n_26/Vol13N26A10.pdf]

la comisión del delito por parte de las personas físicas ${ }^{74}$.

\subsection{Proporcionalidad y prohibición de non bis in ídem: el Caso Asevertrans}

La doctrina ha venido advirtiendo que una mera transposición de modelos de responsabilidad penal produce fricciones en aspectos como el de proporcionalidad de la pena y el non bis in idem. Si se parte de la base de la responsabilidad penal de una gran corporación esto no suscitará mayor debate. Sin embargo, la realidad es que la mayoría del tramado empresarial lo constituyen sociedades que están constituidas por un solo administrador de manera tal que imponer una penal a la persona física (administrador) y a la persona jurídica significa imponer materialmente dos veces la misma a un mismo sujeto dado la confusión que existe entre ambas esferas (la jurídica y la física). En estos casos de empresas pequeñas, como dice Nieto Martín, el administrador socio recibe dos sanciones diferentes, la pena privativa de libertad y una «multa encubierta» a través de la responsabilidad de la empresa ${ }^{75}$.

En relación a esta idea y a propósito de la problemática chilena Van Weezel ha manifestado que la responsabilidad penal de la persona jurídica es un accesorio a la responsabilidad penal de la persona natural y, en este sentido, postula que la forma de comprobar el respeto por el principio de la culpabilidad en la condena a la persona jurídica es verificar si se respeta el non bis in ídem que es una expresión del principio de culpabilidad ${ }^{76}$. En efecto, al castigar a la persona natural por el delito de cohecho y a la persona jurídica por no evitar la realización del delito de cohecho por parte de la persona natural -violando de esta forma el non bis in ídem y el principio de culpabilidad-, se estaría castigando dos veces el mismo hecho. En virtud de ello, Van Weezel advierte que la Ley 20.393 pone en riesgo la vigencia del principio de culpabilidad que es actualmente uno de los pilares del derecho penal chileno ${ }^{77}$.

En la jurisprudencia chilena, el Caso Asevertrans es un buen reflejo de esta situación, a tal punto que el Tribunal Oral en lo Penal de Arica decidió absolver a la empresa Asevertrans por infracción del principio non bis in idem. Esto se da particularmente porque la persona natural condenada es el dueño, representante legal y único agente de la empresa. A juicio del Tribunal, ello implica condenar dos veces a la misma persona por el mismo hecho. En relación con esto, el veredicto dictado por el Tribunal en el Caso Asevertrans es sumamente claro:

"En relación a la responsabilidad penal de Asevertrans, estos sentenciados han resuelto de manera unánime absolver a la misma; por cuanto JF y la empresa respecto de la cual se pide la sanción se identifican uno con otro, tanto es así que quien ejecutó los delitos bases es el propio JF en beneficio de la empresa y por ende él, de modo que se infringiría el non bis in ídem, al valorar dos veces el cohecho de JF"78.

\footnotetext{
${ }^{74}$ STS (Pleno) 154/2016, de 29 de febrero de 2016

75 NIETO MARTÍN, La responsabilidad penal de las personas jurídicas: Un modelo legislativo, 2008, p. 111.

${ }^{76}$ VAN WEEZEL, “Contra”, cit. nota ${ }^{\circ} 46$, p. 129.

${ }^{77}$ VAN WEEZEL, "Contra”, cit. nota n 46, p. 129.

${ }^{78}$ Consejo de Defensa del Estado con Asevertrans Limitada (2015).
} 
NAVAS, Iván; JAAR, Antonia. "La responsabilidad penal de las personas jurídicas en la jurisprudencia chilena".

Otro argumento en el que se basa el tribunal tiene relación con el artículo $4^{\circ}$ de la Ley $\mathrm{N}^{\circ}$ 20.393 que describe el modelo de prevención de delitos que recomienda implementar una empresa para que se entienda que cumple con sus deberes de dirección y supervisión. El tribunal hace énfasis en que la implementación de un modelo de prevención no tiene sentido al ser el imputado el único agente de la empresa:

"Como se aprecia, todo ello (el contenido del modelo de prevención propuesto por la ley en la empresa Asevertrans no era posible, ya que solo JFE era quien formaba parte de la empresa, por lo que no era necesario algún mecanismo de supervigilancia y control, en tanto que todas las funciones de la empresa recaían sobre la misma persona, por ende, más que un defecto de organización de la empresa Asevertrans, fue la propia conducta de JFE, que está fuera del ámbito de la responsabilidad de la persona jurídica, la que origina una responsabilidad penal a su respecto"79.

\section{Reglas de determinación de la pena conforme a la Ley $\mathrm{N}^{\circ} 20.393$ y su aplicación jurisprudencial}

El artículo $8^{\circ}$ de la Ley $\mathrm{N}^{\circ} 20.393$ señala cuáles son las penas que serán aplicables a las personas jurídicas. Estas son:

- Disolución de la persona jurídica o cancelación de la personalidad jurídica.

- Prohibición temporal o perpetua de celebrar actos y contratos con los organismos del estado.

- Pérdida parcial o total de beneficios fiscales o prohibición absoluta de recepción de los mismos por un período determinado.

- Multa a beneficio fiscal.

- Las penas accesorias previstas en el artículo 13.

Por otra parte, el artículo 17 de la Ley No 20.393 establece reglas para determinar la cuantía y la naturaleza de las penas a imponer a la persona jurídica, reglas que se basan en criterios como los montos involucrados en la comisión del delito, el tamaño y la naturaleza de la persona jurídica, la extensión del mal causado por el delito, entre otros. Considerando estas normas, nos interesa preguntarnos cuáles son las penas que han aplicado los tribunales chilenos y si es que ellos han realizado un ejercicio fundado de determinación para aplicarlas conforme al artículo señalado.

Respecto a las penas que se han aplicado en Chile a las personas jurídicas, primero hay que tener presente que, de los seis casos en estudio, en sólo cuatro de ellos hubo condena a la persona jurídica. El caso Ceresita terminó en una suspensión condicional del procedimiento y el Caso Asevertrans en una absolución. En cuanto al Caso Colbún, las penas impuestas a la persona jurídica fueron una multa a beneficio fiscal de 500 UTM, la pérdida del $40 \%$ de los beneficios fiscales y la accesoria de publicación de la sentencia en el diario El Mercurio. En el Caso Pehuenche, se condenó a la persona jurídica a una multa de 680 UTM, la

\footnotetext{
${ }^{79}$ Consejo de Defensa del Estado con Asevertrans Limitada (2015).
} 
Polit. crim. Vol. 13, № 26 (Diciembre 2018) Art. 10, pp. 1027-1054.

[http://www.politicacriminal.cl/Vol_13/n_26/Vol13N26A10.pdf]

prohibición temporal de celebrar actos y contratos con el Estado por el término de cuatro años y a la misma pena accesoria. En el Caso Maggi, las penas impuestas fueron la prohibición absoluta de recepción de beneficios fiscales por el término de dos años, prohibición temporal de celebrar actos y contratos con el Estado por dos años y la misma pena accesoria, además del comiso de dos cheques. Por último, en el Caso Universidad del Mar, las penas impuestas fueron una multa de 2.000 UTM, la pena accesoria de publicación en el Diario Oficial, a costa de la institución, de un extracto de la sentencia condenatoria.

La pregunta que surge en atención a la pena en la persona jurídica es cuál es el razonamiento del tribunal en cada caso para condenar a la persona jurídica a esa pena específica. ¿Cómo se justifica la imposición de esas penas? En términos teóricos cabe sostener que la pena de multa es en muchos casos proporcional al hecho cometido, pero muchas veces no lo es en absoluto al ahorro de la empresa que opera a través de un delito ${ }^{80}$. Desde la práctica penal chilena, la respuesta es que los tribunales de primera instancia no fundamentan su decisión conforme a los criterios de determinación de la pena que establece el artículo 17. En ninguna de las sentencias hay un razonamiento que permita comprender por qué se aplican determinadas penas.

En esta misma situación se basa el Consejo de Defensa del Estado al interponer un recurso de apelación en contra de la sentencia de primera instancia en el Caso Maggi. El organismo público solicita que se reemplace la pena de prohibición absoluta de recepción de beneficios fiscales por dos años por la pena de multa de 200 UTM fundamentando lo siguiente:

"la aplicación de la prohibición de celebrar actos y contratos con organismos del Estado ya impone una limitación para la empresa en su relación con la Administración Pública, así las cosas, la aplicación de la multa, incluso en su mínimo, resulta más acorde con la finalidad de la prevención especial que, en particular tratándose de personas jurídicas, se espera que cumplan las penas impuestas" ${ }^{\text {" } 1}$.

Así también, el organismo público alega que las penas aplicadas no se condicen con el mal causado considerando que:

"estos hechos han ocasionado un perjuicio al estado, que debe ser resarcido, pero, además, debe tenerse en consideración que los delitos de cohecho afectan a la función pública, entendida como el "correcto funcionamiento de la Administración pública", esto es, la función de prestación a los ciudadanos y el cumplimiento de los criterios objetivos correspondientes a los fines del estado social y democrático de derecho" ${ }^{\text {}}$.

Este recurso de apelación fue rechazado por la Corte de Apelaciones de Chillán, la cual confirmó las penas impuestas por el Tribunal de primera instancia sin dar ningún

\footnotetext{
${ }^{80}$ Crítico en este sentido FEIJOO SÁNCHEZ, Bernardo «Las características básicas de la responsabilidad penal de las personas jurídicas en el Código Penal español», en BAJO FERNÁNDEZ, Miguel; FEIJOO SÁNCHEZ, Bernardo; GÓMEZ-JARA, Carlos, Tratado de responsabilidad penal de las personas jurídicas, Navarra, Civitas, 2012, p. 83

${ }^{81}$ Fisco de Chile con Eadez (2014).

${ }^{82}$ Fisco de Chile con Eadez (2014).
} 
NAVAS, Iván; JAAR, Antonia. "La responsabilidad penal de las personas jurídicas en la jurisprudencia chilena".

fundamento para su resolución.

\section{El deber de motivación en las sentencias penales contra personas jurídicas.}

La motivación de las sentencias es una expresión más del debido proceso manifestado en el derecho de las partes a obtener del tribunal una sentencia motivada, es decir, derecho a que el tribunal razone, fundamente e interprete el derecho sobre el objeto de fondo sometido a su conocimiento. Ésta cara del debido proceso corporizada en el derecho a la motivación jurídica lo ha expresado en reiteradas ocasiones el Tribunal Constitucional Español en sentencias como la STC 215/2006 de 3 de julio donde señala "el derecho fundamental a la tutela judicial efectiva comprende el derecho a obtener de los Jueces y Tribunales una respuesta fundada en Derecho, esto es, motivada y razonable".

Ahora bien, si la exigencia de motivación de la sentencia constituye para los ciudadanos un derecho fundamental, simétricamente conforma un deber para el juez. Este deber está positivizado en el art. 342 letra d) del $\mathrm{CPP}^{83}$. Tanto es así que el deber de la motivación de las sentencias penales existe incluso en aquellos procedimientos donde el imputado acepta expresamente los hechos y los antecedentes de la investigación como por ejemplo sucede en el procedimiento abreviado.

En cierta medida podría señalarse que en aquellos procedimientos en que no hay contradicción entre las partes se podría pensar en una rebaja en el estándar de motivación de la sentencia. Sin embargo, esto está claramente prohibido por nuestra legislación y así se señala expresamente en el art. 413 letra d) del CPP que regula los elementos que debe contener la sentencia del procedimiento abreviado. En dicha norma se exige expresamente que la sentencia contenga las razones legales o doctrinales que sirvieren para calificar jurídicamente cada uno de los hechos y sus circunstancias y para fundar su fallo. Estimamos que renunciar a la motivación de una sentencia penal, a pesar de no existir contradicción en los hechos y márgenes de la pena a imponer, sería peligroso por el hecho de que se trata de una consecuencia jurídica que afecta a un derecho fundamental como es el debido proceso y la misma libertad de la persona imputada. La necesidad de motivación de la sentencia penal es en definitiva un límite del Ius Puniendi al ser el proceso penal la forma de ejercicio de él. Sin embargo, el principal argumento para rechazar una ausencia de motivación en procesos donde existe una menor contradicción de los hechos es que mediante su exigencia se asegura una garantía fundamental para el imputado.

En efecto, la sentencia motivada es una doble garantía, esto es, una garantía individual y otra institucional. Su fundamento se encuentra por una parte en la garantía fundamental el debido proceso (garantía individual) y por otra en el principio de legalidad (garantía institucional). En primer lugar, como garantía del debido proceso la función de la motivación de la sentencia permite realiza un control ex post o a posteriori de las razones que tuvo el juez como fundamento de su decisión. Ello contribuye, entre otras cosas, a permitir el ejercicio del derecho a los recursos contra la sentencia. En segundo lugar, como

\footnotetext{
${ }^{83}$ Art. 342 "Las sentencia definitiva deberá contener: d) Las razones legales o doctrinales que sirvieren para calificar jurídicamente cada uno de los hechos y circunstancias y para fundamentar el fallo".
} 
Polit. crim. Vol. 13, № 26 (Diciembre 2018) Art. 10, pp. 1027-1054.

[http://www.politicacriminal.cl/Vol_13/n_26/Vol13N26A10.pdf]

garantía del principio de legalidad, la motivación de la sentencia permite la legitimación de la decisión jurisdiccional a través de una verificación del juez del contenido fáctico de las normas jurídico-penales como requisito de la atribución de responsabilidad penal ${ }^{84}$. Así, la obligación de motivar las sentencias permite afirmar el sometimiento de ellas a la ley y al ordenamiento jurídico. Ahora bien, más allá de ser una garantía procesal, la motivación de la sentencia cumple una función fundamental para el sistema jurídico general que es entregar certeza y previsibilidad del contenido y alcance de las normas jurídicas ${ }^{85}$. Ello evita la aplicación arbitraria y transforma a la jurisprudencia en una fuente secundaria y legítima del derecho penal junto a la ley.

Ahora bien, sentado el deber de motivación y su importancia la discusión el tema siguiente pasa por delimitar la manera de verificación de los hechos con el derecho. En este sentido, en materia penal la interpretación gramatical de las normas penales es completamente insuficiente. Por ejemplo, el art. 390 sanciona "al que mate a otro". Una interpretación gramatical nos diría que aquí se sanciona a el que cause la muerte de otra persona. Pues bien, con este razonamiento cómo respondemos a la pregunta ¿se puede matar por omisión? La omisión no causa nada, de esta forma con la limitada lectura de la norma primaria de comportamiento no podríamos sancionar a la madre que deja de alimentar al hijo y provoca su muerte.

Para resolver los casos, debemos fundamentar jurídicamente y eso exige un proceso de razonamiento lógico fundado en los postulados y avances de la ciencia jurídico penal. En este caso, en la disciplina que cultiva la interpretación del derecho penal: la dogmática penal. Sólo con un fundamento basado en los postulados del derecho penal se da cumplimiento al derecho a una sentencia motivada en derecho. En efecto, existe el derecho de obtener de los órganos jurisdiccionales una respuesta razonada, motivada y congruente con las pretensiones oportunamente deducidas por las partes en cualquier clase de procesos.

En el fondo, la motivación explicita las razones de la decisión, permite controlar la discrecionalidad de los tribunales y habilita la posibilidad de impugnar la decisión mediante las acciones y recursos que establezca el ordenamiento jurídico. Esas razones deben ser jurídicas y tienen como límite la norma de conducta, pero tienen como fundamento la comprensión de los elementos de la norma de conducta. El artículo $8^{\circ}$ de la Constitución exige a todos los órganos del Estado, incluyendo los jurisdiccionales, la publicidad sobre los fundamentos de las decisiones como paso fundamental para verificar su control ${ }^{86}$.

Pues bien, establecido el alcance del deber de motivación de las sentencias, parece necesario aclarar por qué debería preocuparnos el cumplimiento de este deber en las sentencias penales y especialmente en los casos de la responsabilidad penal de las personas jurídicas. La respuesta a ello radica en que la fundamentación del juez en el juzgamiento de

\footnotetext{
${ }^{84}$ HORVITZ LENNON María Inés/LÓPEZ MASLE Julián, Derecho procesal penal chileno, t. II, 2004, p. 341.

${ }^{85}$ ACCATINO SCAGLIOTTI, «La fundamentación de las sentencias: ¿un rasgo distintivo de las judicatura moderna?», en Revista de Derecho (Valdivia), vol. XV, 2003, p. 35.

${ }^{86}$ GARCÍA PALOMINOS, Gonzalo/CONTRERAS VÁZQUEZ Pablo, El derecho a la tutela judicial y al debido proceso en la jurisprudencia del tribunal constitucional chileno, p. 256.
} 
NAVAS, Iván; JAAR, Antonia. "La responsabilidad penal de las personas jurídicas en la jurisprudencia chilena".

una persona jurídica parece ir en contra de toda la tradición jurídica-penal de los últimos 200 años desde que FEUERBACH sistematizara y diera origen a la teoría del delito moderna con base en una persona física como único sujeto de responsabilidad penal ${ }^{87}$. Todos los principios limitadores del Ius Puniendi como por ejemplo el principio de culpabilidad, se construyen bajo el presupuesto de que sujeto de imputación es una persona física con capacidad de acción y a quien se puede reprochar haber hecho un uso de la libertad peligroso para terceros. La expectativa es justamente esa: cómo se fundamentará y se aplicará por parte del juez, una teoría del delito elaborada sobre el presupuesto de una persona física y no sobre un ente jurídico.

Ahora bien, luego del análisis realizado sobre la jurisprudencia existente hasta ahora que se ha pronunciado sobre la responsabilidad penal de las personas jurídicas se puede afirmar una escasa motivación de las sentencias en aquellos casos donde ha tenido que condenar a alguna persona jurídica. En concreto, nos referimos a los casos Áridos Maggi, Colbún y Pehuenche. En estas sentencias existe un mínimo y escaso análisis de las razones legales o doctrinales que le permitieron a los respectivos tribunales calificar los hechos como delictivos para la persona jurídica. Ello implicaría un análisis de cada uno de los requisitos que exige la ley 20.393 en su art. 3 para cada caso concreto que fue sometido a conocimiento del tribunal. Si se revisa las sentencias señaladas, éste análisis simplemente no se encuentra.

Por último, las cuestiones relativas a la capacidad de acción o algunos principios como el de culpabilidad que pudieran cuestionar una verdadera responsabilidad penal de las personas jurídicas, tampoco han sido analizados en mayor medida por la jurisprudencia chilena. Sin embargo, esto puede ser parte de un tema más profundo y que venimos manifestando durante todo el trabajo: la falta de motivación puede explicarse por la dificultar teórica y de encuadre de las principales categorías de la teoría del delito aplicada a entes colectivos. Así, el juez, que se enfrenta con una persona jurídica a la que debe aplicar el complejo aparato dogmático penal se enfrenta a un tremendo desafío. Es aquí donde la doctrina debe proponer alternativas y construcciones que como las que se han señalado en el trabajo para que, respetando el principio de legalidad, le faciliten la labor al juez conforme a la constitución y las normas legales.

\section{Conclusiones.}

Revisado el panorama jurisprudencial relativo a la responsabilidad penal de las personas jurídicas se puede afirmar que los tribunales chilenos han verificado la concurrencia de los tres requisitos que impone la Ley $\mathrm{N}^{\mathrm{o}} 20.393$ en su artículo $3^{\circ}$ para atribuir responsabilidad. Sin embargo, esto se ha realizado en forma insuficiente. En su aplicación no se ha verificado si es que las personas naturales que ostentan esos cargos determinados realmente ejercen actividades de administración y supervisión dentro de la empresa, ni tampoco se ha profundizado en las razones por las cuales consideran que el delito fue cometido en interés directo de la persona jurídica y no en el sólo interés de la persona natural. Respecto al tercer requisito - que la comisión del delito sea consecuencia del incumplimiento por parte de la

\footnotetext{
${ }^{87}$ FEUERBACH, Lehrbuch des gemeinen in Deutschland geltenden Peinlichen Rechts, 1801,
} 
Polit. crim. Vol. 13, No 26 (Diciembre 2018) Art. 10, pp. 1027-1054.

[http://www.politicacriminal.cl/Vol_13/n_26/Vol13N26A10.pdf]

persona jurídica de los deberes de dirección y supervisión - se han generado dos problemas importantes. El primero se refiere a que se ha considerado que el no tener un modelo de prevención de los delitos implica necesariamente que se están incumpliendo los deberes de dirección y supervisión y el segundo problema dice relación con la falta de justificación de que la empresa no implementó otros mecanismos para evitar la comisión del delito.

En cuanto al principio de culpabilidad, la jurisprudencia chilena no ha hecho una referencia clara a él al momento de condenar a una persona jurídica, y, en el único caso en que lo ha hecho ha terminado por absolverla. Esta situación da para preguntarse si es que los tribunales evitan referirse a él porque efectivamente es el "incómodo principio de culpabilidad"88. Finalmente, la motivación hecha por los tribunales al momento de imponer una pena determinada es insuficiente. Dicha situación puede representar un problema relativo a una posible vulneración de garantías fundamentales, en especial, con el derecho al debido proceso de las personas que abarca el derecho a que las sentencias estén motivadas y fundamentadas por los tribunales. Ello implica entre otras cosas un razonamiento que señale el sentido y alcance de las normas jurídicas para que así se dé lugar a la interpretación y aplicación del derecho conforme a los hechos acaecidos.

${ }^{88}$ VAN WEEZEL, “Contra”, cit. nota n ${ }^{\circ} 46$, p. 129. 
NAVAS, Iván; JAAR, Antonia. "La responsabilidad penal de las personas jurídicas en la jurisprudencia chilena".

\section{Bibliografía}

ARTAZA VARELA, Osvaldo, La empresa como sujeto de imputación de responsabilidad penal, Madrid: Marcial Pons, 2013.

BALMACEDA HOYOS, Gustavo; GUERRA ESPINOSA, Rodrigo, Políticas de prevención de delitos en la empresa, Santiago de Chile, Thomson Reuter, 2014.

BOFILL GENZSCH, Jorge, "Estructuras de imputación y prevención de delitos al interior de la persona jurídica", en WILENMANN VON BERHATH, Javier (coord.), Gobiernos Corporativos, Aspectos esenciales de las reformas a su regulación, Santiago, Universidad Adolfo Ibáñez, 2011, páginas entre las cuales se encuentra el artículo.

CAÑAS ARANDA, Macarena, "Responsabilidad penal de las personas jurídicas, Suspensión condicional del procedimiento Industrias Ceresita S.A., Revista Jurídica del Ministerio Público $\mathrm{N}^{\circ}$ 55, (2013), pp. 79-92.

COUSO SALAS, Jaime, Fundamentos del derecho penal de culpabilidad, Valencia: Tirant lo Blanch, (2006).

COLLADO GONZÁLEZ, Rafael, Empresas criminales, Santiago de Chile: Thomson Reuters, 2013.

CORDERO QUINZACARA, Eduardo, "El derecho administrativo sancionador y su relación con el derecho penal”, Revista de Derecho de Valdivia, n² 2, (2012), pp. 131-157

CORDERO VEGA, Luis, Casos destacados de derecho administrativo, t. III, Santiago de Chile: Thomson Reuters, 2015.

COUSO SALAS, Jaime, Fundamentos del derecho penal de la culpabilidad, Editorial Tirant lo Blanch, Valencia, 2006.

CURY URZÚA, Enrique, Derecho Penal. Parte general, $11^{\mathrm{a}}$ ed., 2011, ediciones PUC, 2005.

FEIJOO SÁNCHEZ, Bernardo «Las características básicas de la responsabilidad penal de las personas jurídicas en el Código Penal español», en BAJO FERNÁNDEZ, Miguel; FEIJOO SÁNCHEZ, Bernardo; GÓMEZ-JARA, Carlos, Tratado de responsabilidad penal de las personas jurídicas, Navarra, Civitas, (2012), pp. 67-91

FRANK, Reinhard, «Über den Aufbau des Schuldbegriffs», FS der Gießener Juristenfakültat zum 300 jährigen Bestehen der Universität Gießen, 1907.

GARCÍA CAVERO, Percy, "Esbozo de un modelo de atribución de responsabilidad penal de las personas jurídicas", Revista de Estudios de la Justicia, No 16, 2012, pp. 55 74.

GARCÍA CAVERO, Percy, La responsabilidad penal del administrador de hecho de la empresa: Criterios de imputación, Barcelona: Bosch, 1999.

GARCÍA PALOMINOS, Gonzalo/CONTRERAS VÁZQUEZ, Pablo, "El derecho a la tutela judicial y al debido proceso en la jurisprudencia del tribunal constitucional chileno”, Revista Estudios Constitucionales, 2013, pp. 229-282.

GARRIDO MONTT, Mario, Derecho penal. Parte general, t. II, Editorial Jurídica de Chile, 1997.

GOLDSCHMIDT, James, La concepción normativa de la culpabilidad, (traducción de Margarethe de Goldschmidt y Ricardo C. Nuñez publicada en 1930 bajo el título Normativer Schuldbegriff) 2a ed., B de F, Montevideo, 2002. 
Polit. crim. Vol. 13, № 26 (Diciembre 2018) Art. 10, pp. 1027-1054.

[http://www.politicacriminal.cl/Vol_13/n_26/Vol13N26A10.pdf]

GÓMEZ-JARA DÍEZ, Carlos, La culpabilidad penal de la empresa, Madrid: Marcial Pons, 2005.

HEINE, Günter Die strafrechtliche Verantwortlichkeit von Unternehmen, Nomos, BadenBaden, 1995.

HEINRICH, Bern, Strafrecht. Allgemeiner Teil, $4^{\text {a }}$ ed., Kohlhammer, Deutschland, 2014.

HERNÁNDEZ BASUALTO, Héctor, "La introducción de la responsabilidad penal de las personas jurídicas en Chile", Política Criminal, Vol. 5, № 9, 2010, pp. 207-236.

HORVITZ, María Inés/LÓPEZ MASLE, Julian, Derecho procesal penal chileno, t. II, Santiago de Chile, Editorial Jurídica de Chile, 2004.

JESCHECK Hanz-Heinrich /WEIGEND Thomas (1996), Lehrbuch des Strafrecht. Allgemeiner Teil, $5^{\text {a }}$ edición, Berlin. Duncker \& Humblot.

KINDHÄUSER, Urs, «Culpabilidad jurídico-penal en el estado democrático de derecho», Revista de derecho, vol. 10, 2009.

LAMPE, Ernst-Joachim, «Systemunrecht und Unrechtssysteme, ZStW, n 106, 1994.

MATUS ACUÑA, Jean Pierre, "Informe sobre el proyecto de ley que establece la responsabilidad legal de las personas jurídicas en los delitos de lavado de activos, financiamiento del terrorismo y delitos de cohecho que indica, ensaje $n^{\circ}$ 018-357", Revista Ius et Praxis, vol. 15, núm 2, 2009, pp?

MAÑALICH, Juan Pablo, "Organización delictiva. Bases para su elaboración dogmática en el derecho penal chileno", Revista Chilena de Derecho, vol. 38 N $^{\circ} 2$, 2011, pp. 279-310.

NIETO MARTÍN, Adán, La responsabilidad penal de las personas jurídicas: Un modelo legislativo, Iustel, Madrid, 2008.

ROBLES PLANAS, Ricardo, «Pena y persona jurídica: crítica del artículo 31 bis CP», Diario La Ley, 2011.

ROXIN, Claus, Derecho penal. Parte general, t. I, (traducción Diego Luzón Peña et al) Madrid: Civitas, 1997.

SEGOVIA ARANCIBIA, Antonio, "Modelos de atribución de responsabilidad penal a las personas jurídica en la Ley 20.393”, Revista Jurídica del Ministerio Público, N 43, junio, 2010.

SCHMITT Carl, Posiciones ante el derecho, (traducción de Montserrat Herrero), Madrid: Editorial Tecnos, reimpresión 2015.

SILVA SÁNCHEZ, Jesús "La responsabilidad penal de las personas jurídicas en derecho español", en: Comunicaciones en Propiedad Industrial y Derecho de la Competencia, $\mathrm{n}^{\mathrm{o}} 65$ (Enero-Abril), 2012, pp. 7-36.

VAN WEEZEL, Alex, "Contra la responsabilidad penal de las personas jurídicas", Política Criminal, Vol. 5, No 9, 2010, pp. 114-142.

ZUGALDÍA ESPINAR, José Miguel, La responsabilidad criminal de las personas jurídicas, de los entes sin personalidad y de sus directivos: Tirant lo Blanch, Valencia, 2013. 